\title{
Klemen Grabnar
}

\section{Je ne menge poinct de porcq: zgodnja parodična maša Orlanda di Lassa}

\author{
ET SUEM, QUI, CUM UNGULAM PLENE DIVIDAT, NON RUMINAT. \\ Lv 11.7 (Nova vulgata)
}

»Le plus divin Orlande«, "princeps musicorum», »mirabile Orlando" - to so le nekateri izmed mnogih vzdevkov, ki si jih je Orlando di Lasso (1530/15321594), zagotovo eden najvidnejših skladateljev 16. stoletja, prislužil že za časa svojega življenja. ${ }^{1}$ Uveljavil se je in si pridobil precejšen ugled že zgodaj v svoji dolgoletni karieri, kar je bila med drugim posledica njegovih številnih potovanj. V zgodnjih letih je deloval v rodnem Monsu (do 1544), v različnih italijanskih mestih (1544-1554) in v Antwerpnu (1554-1556), nato pa se je ustalil v Münchnu, kjer je bil od leta 1563 maestro di cappella na tamkajšnjem dvoru. Njegov opus je zelo obsežen - napisal je kar blizu dva tisoč kompozicij (med njimi npr. maše, motete, madrigale, šansone in nemške pesmi). Lassova dela so bila izjemno razširjena, zlasti po srednji in zahodni Evropi, kjer so v glasbenih knjižnicah in arhivih še danes ohranjene mnoge njegove kompozicije, tako v rokopisni kot tudi tiskani obliki. ${ }^{2}$ Nekaj njegovih izvirnih tiskov in večje število prepisov njegovih del lahko najdemo tudi v slovenskih knjižnicah. ${ }^{3}$

Med tovrstnimi ohranjenimi prepisi je tudi Missa super Je ne menge poinct de porcq, ki se je delno ohranila v dveh rokopisih iz ok. leta 16oo, danes

1 Uporabljajo se različne oblike njegovega imena: ena izmed pogostejših je italijanizirana oblika (Orlando di Lasso), ki jo je često uporabljal tudi sam. Poleg te pa se med drugimi uporabljajo še francoski različici (Roland ali Orlande de Lassus) in nekoliko redkeje latinizirana (Orlandus Lassus).

2 Lassova glasba je bila priljubljena še desetletja po njegovi smrti; še leta 1687 je bila denimo v Parizu pod naslovom Missa quatuor vocum ad imitationem moduli ponatisnjena Missa Iager (poznana tudi kot Missa Venatorum).

3 Več o tem piše Kokole, »Musical Repertoire, «171-90. 
hranjenih v Rokopisni zbirki Narodne in univerzitetne knjižnice v Ljubljani. Prvič je bila natisnjena leta 1570 v Lassovi drugi knjigi maš, ki velja za njegovo prvo ohranjeno mašno zbirko. ${ }^{4}$ Večina maš v zbirki je nastala že pred letom 1570, kar dokazuje velika rokopisna korna knjiga iz ok. leta 1565, ki jo hranijo v Münchenski državni knjižnici. Provenienca obeh zgoraj omenjenih rokopisov ni popolnoma jasna, verjetno pa je, da sta bila do 18. stoletja del škofijskega arhiva v Gornjem Gradu. Rokopis 232, v katerem je ohranjena skupaj z drugimi Lassovimi mašami, pripada tipu t. i. korne knjige. ${ }^{6}$ Gre za tip knjige, kjer so na odprtih straneh (verso in recto) vsi glasovi, ki so bili izvajani hkrati, zapisani posebej. Običajen vrstni red poteka od zgornjega glasu, zapisanega na levi strani zgoraj, do spodnjega, zapisanega na desni strani spodaj; vsi glasovi so istočasno prehajali na naslednje strani. Omenjenemu rokopisu manjka 1. folij, kjer sta se morala nahajati parta za sopran in tenor z zapisom prvega stavka maše (Kyrie) in začetka drugega stavka (Gloria). Rokopis 285 pa je v obliki glasovnega zvezka - vsebuje notni zapis za enega izmed pevskih glasov, in sicer za tenor. Zvezek vsebuje tenorski part več Lassovih maš, med njimi tudi obravnavano?

Polifona maša, tj. večglasna uglasbitev besedil mašnega ordinarija, ${ }^{8}$ je imela v 16. stoletju že nekaj zgodovine in kar precej predzgodovine za seboj. Besedila mašnega ordinarija so bila v drugačni obliki in vlogi kot ju poznamo danes pogosto kot del liturgije v nekaterih liturgičnih skupnostih prisotna že $\mathrm{v}$ prvih stoletjih, $\mathrm{v}$ današnjem pomenu pa so bila $\mathrm{v}$ širšem vključena $\mathrm{v}$ mašno bogoslužje v različnih obdobjih. ${ }^{9}$ Prve uglasbitve so znane iz 10. stoletja in so enoglasne, prve večglasne uglasbitve pa so iz 12. stoletja. Do 14. stoletja je bila vsaka uglasbitev posameznega besedila običajno mišljena kot zaključena celota, samostojna skladba, za prvo mašo, kjer je vidna zamisel uglasbitve skupine besedil mašnega ordinarija kot ene same glasbene kompozicije (se pravi maša kot eno delo iz več stavkov), pa velja Messe de Nostre Dame Guillauma de Machauta iz sredine 14. stoletja. Maše v smislu ene kompozicije s svojskim glasbenim izrazom so se vse bolj pogosto komponirale sicer šele od začetka 15. stoletja; sprva so nastajali le pari (npr. Gloria-Credo), postopoma pa se je uglasbljevalo vseh pet delov. V začetku 15. stoletja so glasbeno enovitost maše

4 V obliki glasovnih zvezkov jo je z naslovom Quinque missae v Benetkah natisnil slavni organist, skladatelj in založnik Claudio Merulo (da Correggio). Posvečena je salzburškemu nadškofu Johannu Jakobu Khuenu von Belasiju in vsebuje štiri štiriglasne in eno petglasno mašo, vse nastale v zgodnjem münchenskem obdobju. Missa super Ie ne menge poinct de porcq je bila natisnjena še dvakrat: leta 1581 in 1588. Gl. Leuchtmann in Schmid, Seine Werke in zeitgenössischen Drucken, 1: $286-87,2: 43-44,180$.

5 D-Mbs, Mus Ms 2746.

6 SI-Lnr, Ms 232, f. 26r (2r)-33r (9r).

7 SI-Lnr, Ms 285, f. 17v-22.

8 Besedila si po vrsti sledijo: Kyrie, Gloria, Credo, Sanctus z Benedictusom in Agnus Dei.

9 Kyrie eleison je bil del zahodnega mašnega bogoslužja že vsaj v 6. stoletju, Gloria naj bi bila prisotna od 7. stoletja, Credo na širšem evropskem področju od 11. stoletja, Sanctus naj bi postal del mašnega bogoslužja med 1. in 5. stoletjem, Agnus Dei pa v poznem 7. stoletju. Gl. npr. McKinnon, »Mass." 
do določene mere dosegli s tem, da so bili vsi njeni deli na splošno komponirani v istem slogu, že kmalu pa so se tekom 15. stoletja izoblikovali predvsem trije načini učinkovitega medsebojnega povezovanja stavkov maše: $\mathrm{z}$ uporabo enakega tematskega materiala, pri čemer se vsak stavek začne enako oz. podobno (to so maše $\mathrm{z}$ mottom); $\mathrm{z}$ uporabo iste, že prej obstoječe melodije (tj. cantusa firmusa), ki je temelj vseh mašnih stavkov (take maše se imenujejo tenorske maše); in z uporabo istega skladateljskega postopka (skladatelji so mašne stavke gradili na primer s pomočjo kanonov). Našteti načini medsebojnega povezovanja stavkov so se lahko med seboj tudi prepletali.

V 16. stoletju so se pojavili novi postopki povezovanja mašnih stavkov. Med njimi je postal najpogostejši ta, pri katerem je za osnovo služilo glasbeno gradivo že obstoječe kompozicije, vendar pri tem (v nasprotju s kompozicijskimi praksami prejšnjih stoletij) temelja za novo skladbo ni predstavljal le en sam glas predloge, temveč vsi glasovi. Skladatelj je za osnovo lahko uporabil posamezne dele šansone, madrigala ali moteta in jih na različne načine predelal - variiral, razširil ipd. Tako komponirane maše se najpogosteje označujejo $\mathrm{z}$ izrazom parodične maše. ${ }^{10}$ Pri parodični tehniki komponiranja torej ne gre zgolj za citiranje, temveč za temeljito predelavo modelne kompozicije, kjer je gradivo modela razporejeno na novo, z vmesno popolnoma novo komponirano glasbo. Tako modelna kompozicija služi le kot izhodišče - osnova, na podlagi katere je dosežena glasbena enovitost pri uglasbitvi besedil mašnega ordinarija.

Prikaz takega načina komponiranja maše je v traktatu El melopeo y maestro iz leta 1613 podal Pietro Cerone. ${ }^{11}$ Čeprav je opis kratek, nam kljub temu posreduje osnoven obris procesa oblikovanja parodične maše. Pri tem je Cerone izhajal prav iz kompozicijske prakse sredine in druge polovice 16. stoletja, tj. čas, ko je deloval Lasso. Poglavitne točke njegovega prikaza so:

1. Začetek vsakega stavka maše mora biti podoben začetku predloge, kar se doseže z uporabo enakega glasbenega gradiva, ki pa je vsakokrat nekoliko drugače kontrapunktsko obdelano.

2. Drugi odsek prvega stavka (Christe eleison) je lahko osnovan na katerem

10 Grški izraz $\pi \alpha \rho \omega \delta_{i}$ ia so s tovrstno mašno ustvarjalnostjo povezovali predvsem nemški glasbeniki 16. in zgodnjega 17. stoletja. Ob tem velja izpostaviti tisk maše Jacoba Paixa $\mathrm{z}$ naslovom Missa: Parodia mottetae Domine da nobis auxilium Th. Crequilonis, ki je izšla leta $1587 \mathrm{v}$ Lauingenu; naslov Paixove maše je imel namreč močan vpliv na oblikovanje besedne zveze parodična maša v 19. stoletju. Pri njeni uveljavitvi sta imela pomembno vlogo August Wilhelm Ambros, avtor vplivne knjige Geschichte der Musik, in Peter Wagner z monografijo Geschichte der Messe. Zlasti med angleškimi muzikologi pa je razširjeno poimenovanje imitacijska maša. Izraz je vpeljal Lewis Lockwood, "On 'Parody' as Term and Concept, "560-75. Ker parodične maše niso v nikakršni povezavi s porogljivim posnemanjem, se je s tem izrazom med drugim skušalo izogniti danes negativnemu prizvoku besede parodija. Literature, ki razlaga različne aspekte parodije v glasbi, je veliko, med njimi osnoven pregled na primer podaja prispevek Armina Brinziga idr., »Parodie und Kontrafaktur,«1394-1416.

11 Cerone se je pri svojem opisu močno naslonil na starejše teoretsko delo Ragionamento di musica Pietra Pontia. 
izmed motivov notranjih fraz predloge, lahko pa je komponiran povsem na novo.

3. Začetek tretjega odseka (Kyrie II) lahko skladatelj oblikuje po svoje, lahko pa uporabi tudi motiv katere izmed notranjih fraz predloge.

4. Zaključki vseh stavkov maše morajo izkazovati podobnost $\mathrm{z}$ zaključkom predloge.

5. Ni nujno, da notranji odseki vsakega stavka kadencirajo na glavni stopnji, pri čemer pa se dva zaporedna odseka ne smeta zaključiti na isti stopnji.

6. Bolj ko se skladatelj pri komponiranju maše poslužuje motivov notranjih fraz predloge, boljša in hvalevrednejša je maša.

Do danes se je ohranilo okoli 60 Lassovih maš; natančnejšo opredelitev števila maš ovira dejstvo, da je poleg nesporno avtentičnih še nekaj takih maš, pri katerih je Lassovo avtorstvo sporno. Velika večina njegovih maš je parodičnih. ${ }^{12} \mathrm{~V}$ tem se njegov opus bistveno ne razlikuje od opusov njegovih sodobnikov. ${ }^{13}$ Lasso je za osnovo svojih parodičnih maš uporabil zelo različne predloge. Nabor obsega lastne in tuje kompozicije različnih žanrov - motete, nemške pesmi, šansone in madrigale - in odraža njegovo široko poznavanje tedanjih slogov in oblik. Pri komponiranju maš, napravljenih na osnovi skladb drugih skladateljev, je zlasti v zgodnejšem obdobju v največji meri posegal po šansonah.

Obravnavana Lassova maša je osnovana po šansoni Je ne menge point de porc Claudina de Sermisyja (ok. 1490-1562), ${ }^{14}$ poleg Clémenta Janequina (ok. 1485-po 1558) enega najvidnejših predstavnikov pariške šansone, ki je cvetela sredi 16. stoletja v Franciji. Pariške šansone so znane iz tiskanih zbirk, ki jih je v Parizu izdajal Pierre Attaingnant. Med leti 1528 in 1552 je izdal čez 15 zbirk, v katerih je izšlo ok. 1500 šanson. Šansona Je ne menge point de porc je izšla v četrti knjigi šanson za štiri glasove, ki jo je Attaingnant izdal skupaj s Hubertom Julletom v Parizu leta $1538 .{ }^{15}$

Po vsebinski plati so šansone največkrat prežete z ljubezensko tematiko, kar omenjeno šansono postavlja med izjeme. Njena vsebina je namreč nedvomno skatološka, saj opisuje prašičeve nečednosti:

Je ne menge point de porc.

Telle que je vois dire,

S'il a mengé cent estrons,

Il ne s'en fera que rire.

Il les tourne, il les vire,

12 Gl. Orlich, Parodiemessen von Orlando di Lasso.

13 Giovanni Pierluigi da Palestrina, poleg Lassa eden izmed velikanov vokalne polifone glasbe 16. stoletja, je denimo od ohranjenih 104 avtor 53 parodičnih maš.

14 Predloga maše dolgo ni bila poznana. Tako podrobno obravnavo dela zaman iščemo tudi v zadnji obsežni sintezi o Lassovih parodičnih mašah Rufine Orlich.

15 Quart livre, f. 2v-3. Sodobna izdaja šansone je na voljo v zbranih delih: Sermisy, Opera omnia, 127-30. 
Il leur rit et puis les mort.

Je ne menge point de porc.

Le porc s'en alloit jouant

Tout au long d'une rivière.

Il veit ung estron nouant,

Il luy print a faire chere,

Disant en ceste maniere:

« Estron nouant en riviere,

Rend toy ou tu es mort. "

Je ne menge point de porc. ${ }^{16}$

Sermisyjeve šansone izkazujejo glede na teksturo tri načine oblikovanja glasbenega stavka: izrazito homofono $\mathrm{z}$ jasno izpostavljeno melodijo v zgornjem glasu, $\mathrm{v}$ razgibani homofoniji in $\mathrm{v}$ enostavni polifoniji, kjer je glasbeno gradivo obravnavano v preprosti imitaciji kratkih motivov. ${ }^{17}$ Šansona Je ne menge point de porc po svoji teksturi nekoliko izstopa iz povprečja, saj se v njej družijo vsi trije opisani načini oblikovanja, kar kompozicijo v veliki meri dela razgibano. Sermisy tako uporablja postopek imitacije, pri čemer je vrstni red vstopanja posameznih glasov vedno drugačen; združuje različne skupine glasov in jih sopostavlja eno poleg druge (zgornja glasova nastopita skupaj in spodnja skupaj ali pa zgornji glas posebej in spodnji trije skupaj); poslužuje pa se tudi stroge homofonije. Kompozicija je razgibana tudi po ritmični plati, skladatelj prav tako menja metrum (iz dvodobnega v tridobnega in nazaj). Dolžina glasbenih fraz se ozira na dolžine verzov, kar je značilno za pariške šansone. To se kaže v tem, da kadence, ki zaključujejo fraze, pogosto sovpadajo s koncem verzov. Skupna značilnost, ki šansono druži z drugimi pariškimi šansonami, je tudi silabičnost. To pomeni, da vsakemu zlogu besedila v glavnem pripada en ton. Čeprav Sermisyjeve šansone niso deskriptivne do te mere kot denimo Janequinove, ${ }^{18}$ je kljub temu mogoče prepoznati določene metode, ki na poseben način odražajo besedilo v glasbi. ${ }^{19} \mathrm{~V}$ obravnavani šansoni se kažejo na primer v taktih 17 in 18 , kjer se $\mathrm{v}$ zgornjem glasu na besedah »Il les tourne « s postopom D-B in na besedah »il les vire« s postopom B-D-B v glasbi odraža pomen besed (gl. glasbeni primer 1). V taktu 21 pa je denimo beseda »mort« izpostavljena tako, da na

16 Ne jem svinjine. / Takole vam povem: / čeprav je (pujs) pojedel sto iztrebkov, / se jim le smeji; / obrača in suka jih, / se jim reži, nato jih zgrabi. / Ne jem svinjine. / Pujs je razigrano odšel / vzdolž rečnega brega. / Zagledal je plavajoči iztrebek, / ga zajel, da bi si ga privoščil / in takole porekel: / »V reki plavajoči iztrebek, / predaj se, če ne je po tebi.«/ Ne jem svinjine. (Prevod je avtorjev). Pisec besedila šansone ni znan.

17 O pariških šansonah gl. npr. Brown in Stein, Music in the Renaissance, 191-97. Osnovno o Sermisyjevih šansonah pa piše Isabelle Cazeaux v uvodu k 3. zvezku zbranih del.

18 Najbolj prepoznaven primer deskriptivne šansone je gotovo Janequinova La bataille s številnimi onomatopoetičnimi učinki.

19 Eden izmed pomenov tedanjega zbliževanja glasbe in besede je, da so humanistično naravnani skladatelji 16. stoletja v okviru takratnih pogledov in spoznanj utirali pot oživljanju antične kulture. 
mestu njenega nastopa prvič vsi glasovi kadencirajo naenkrat (gl. glasbeni primer 2).

Glasbeni primer 1: Claudin de Sermisy, Je ne menge point de porc, t. 17-19.

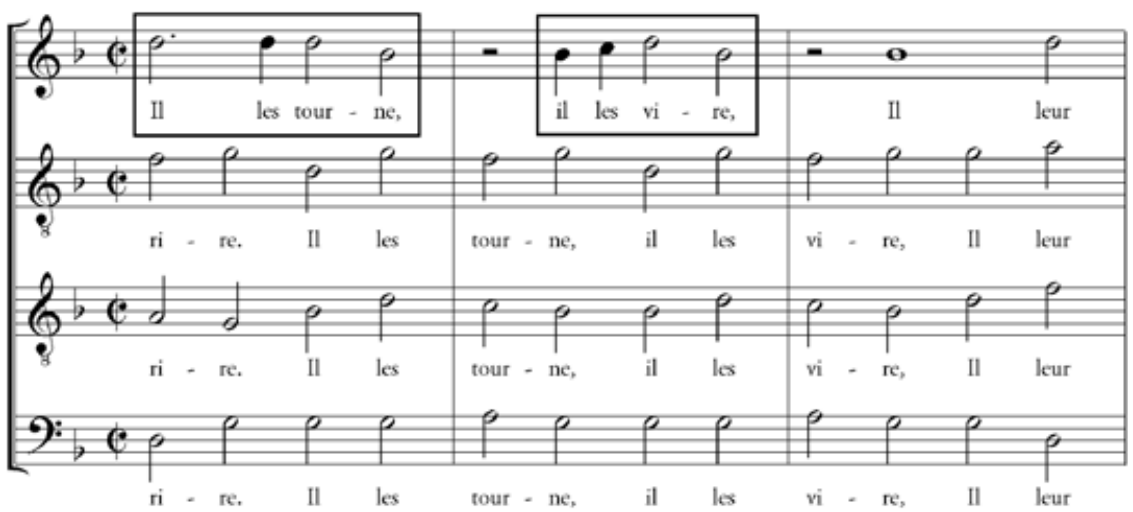

Glasbeni primer 2: Claudin de Sermisy, Je ne menge point de porc, t. 20-21.

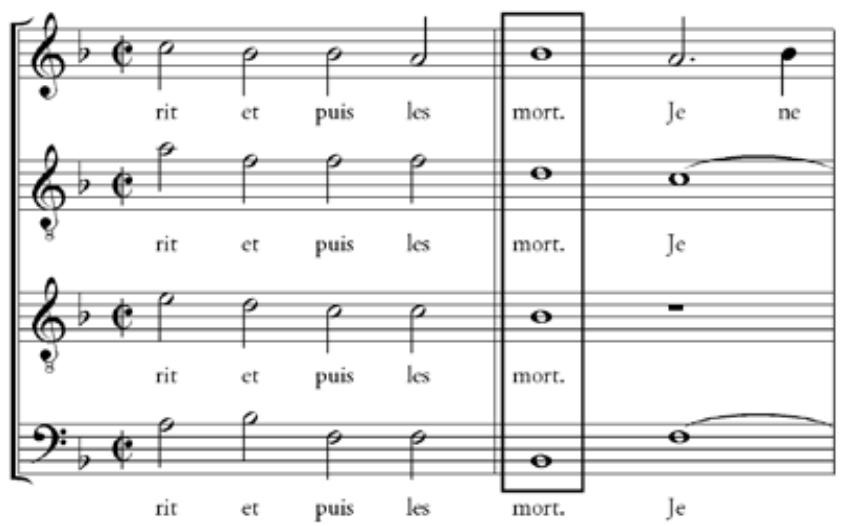

Skladatelj je posebej učinkovito izpostavil premi govor (»'Estron nouant en riviere, / Rend toy ou tu es mort'«), ki je uglasbljen strogo homoritmično in predstavlja edino mesto, kjer imajo popolnoma vsi glasovi hkrati isto besedilo, poleg tega pa se na ključnih besedah metrum zamenja iz dvodobnega $\mathrm{v}$ tridobnega (gl. glasbeni primer 3). 
Glasbeni primer 3: Claudin de Sermisy, Je ne menge point de porc, t. 37-41.

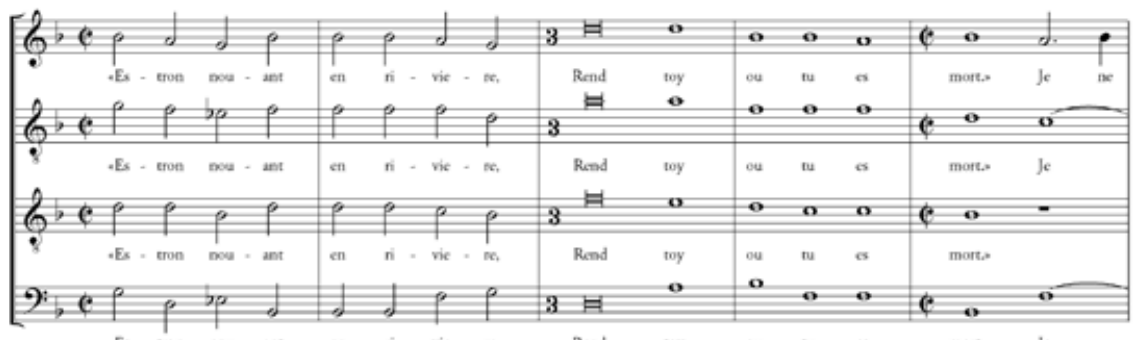

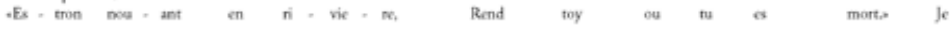

S temi in podobnimi enostavnimi, a prefinjenimi glasbenimi sredstvi je Sermisyju uspelo izpostaviti duhovitost besedila. Tako je tudi postopek imitacije, ki je sicer bolj značilen za resnobne kompozicije, kot so npr. moteti, v tem primeru uporabljen za dosego duhovitosti. Sermisy je z glasbo nedvomno presegel trivialnost samega besedila.

Lassova parodična maša po šansoni Je ne menge point de porc pripada tipu kratkih maš, imenovanih missae breves. ${ }^{20}$ Zanjo je značilno, da ni obsežna, ima več popolnoma homofonih delov in je pretežno silabična. ${ }^{21}$ Pričetek maše je nesporno močno vezan na predlogo (gl. glasbeni primer 4), ki je nemudoma prepoznavna.

Glasbeni primer 4: Orlando di Lasso, Missa super Je ne menge poinct de porcq, Kyrie, t. 1-6 (zgoraj); in Claudin de Sermisy, Je ne menge point de porc, t. 1-6 (spodaj).
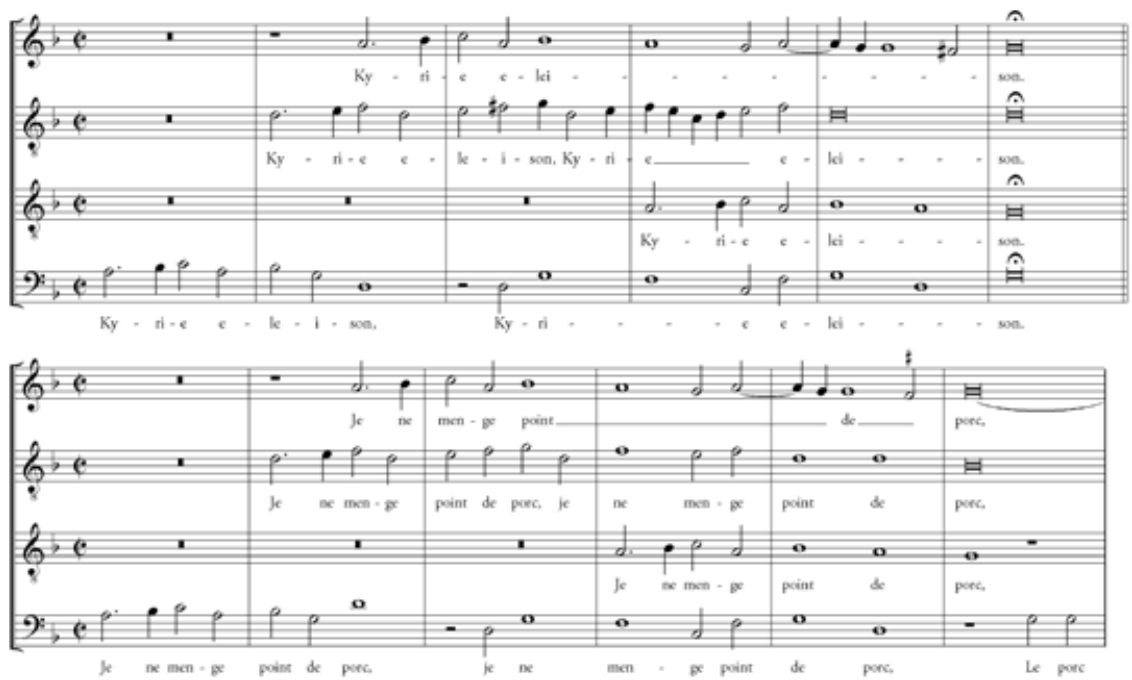

20 Le-ta obsega 281 taktov, medtem ko npr. Lassova najdaljša maša obsega kar 609 taktov. Gl. Orlich, Parodiemessen von Orlando di Lasso, 313-15.

21 Sodobna izdaja maše je dostopna v zbranih delih: Lasso, Messen 1-9, 1-24. 
Začetek modela je $\mathrm{z}$ neznatnimi spremembami skorajda verno citiran. Ker ima besedilo začetka prvega stavka (»Kyrie eleison«) enako število zlogov kot začetek besedila predloge (»Je ne menge point de porc«), tj. sedem, skladatelju na ta način glasbe ni bilo treba znatno predrugačiti. Lasso se je na uvodno motivično gradivo predloge oziral tudi pri snovanju začetka stavkov Credo in Sanctus, medtem ko sta začetek drugega stavka (Gloria) in prva polovica zadnjega stavka (Agnus Dei) komponirana $\mathrm{z}$ uporabo novega glasbenega gradiva. Lasso tako maše ni oblikoval povsem v skladu s prvo točko Ceronejevega prikaza.

Če se ozremo na naslednjo Ceronejevo trditev o oblikovanju drugega odseka prvega stavka (Christe eleison), ugotovimo, da je Lasso izbral prvo izmed običajnih postopkov in Christe osnoval na gradivu s sredine predloge. Nekoliko pa se je odmaknil od običajne prakse pri komponiranju tretjega odseka (Kyrie II), ko se je poslužil gradiva z začetka predloge.

Zaključki vseh stavkov - razen predzadnjega (Sanctus) - so, čeprav se je enkrat od predloge oddaljil bolj, drugič manj, osnovani na motiviki zaključka modelne kompozicije. Tudi v tem se je Lasso tako le nekoliko odmaknil od Ceronejevega prikaza. Nastopi kadenc pa so docela v skladu s Ceronejevo razlago.

Pri komponiranju mašnih stavkov se je, kot je to običajno, bolj ali manj posluževal tudi motivov notranjih fraz predloge. Posebnost pa se kaže v tem, da je pri komponiranju delov, ki so popolnoma svobodni, neodvisni od predloge, vendarle izhajal iz sloga modela in mašo na ta način stilno zaokrožil. ${ }^{22}$

Lasso se pri skladanju maše po Je ne menge point de porc ni vedno oziral na običajno prakso oblikovanja parodične maše, kot jo je na neki način kodificiral Cerone. Razlogov za to je verjetno več. Kot najočitnejši se kaže ta, da zaradi kratkosti uglasbitve mašnega ordinarija ni bilo veliko možnosti za uporabo in razvoj glasbenega gradiva predloge. ${ }^{23}$ Enega izmed razlogov bi gotovo lahko našli tudi v tem, da Lasso ni hotel zapasti v shematičnost in ustvariti neizrazite, povprečne kompozicije. Nenazadnje lahko pomemben dejavnik vidimo v strukturi predloge - njen sklepni del je namreč le nekoliko spremenjena oblika začetnega dela. Glede na to skladatelj začetka drugega stavka (Gloria), ki v liturgiji nastopi neposredno za prvim (Kyrie), ni mogel oblikovati $\mathrm{z}$ enakim glasbenim gradivom, kot je prisotno v sklepu predhodnjega stavka, $\mathrm{v}$ katerem je bilo gradivo $\mathrm{v}$ vsakem primeru možno v kratki časovni oddaljenosti slišati dvakrat. Nekaj podobnega velja za konec predzadnjega (Sanctus) in začetek zadnjega stavka (Agnus Dei). ${ }^{24}$

22 Po mnenju nekaterih muzikologov to kaže na skladateljevo kompozicijsko fleksibilnost. Prim. Orlich, Die Parodiemessen von Orlando di Lasso, 163.

23 Prim. npr. Schalz, Komposition des Gloria, 372-73.

24 Drugi del predzadnjega stavka (Benedictus) je bil namreč v tedanji liturgiji navadno izvajan ločeno od prvega dela in je nastopil tik pred zadnjim stavkom. 
Vprašanje, ki se danes marsikomu porodi že ob pogledu na naslov maše, je, zakaj je Lasso za predlogo maše, ki je takrat veljala za osrednjo liturgičnoglasbeno obliko, vzel dotično Sermisyjevo šansono z nezmotljivo posvetnim besedilom; še več, $\mathrm{z}$ naravnost trivialno vsebino.

V muzikološki literaturi obravnavana maša velja za enega najskrajnejših primerov uporabe posvetne skladbe v liturgični glasbi, ${ }^{25} \mathrm{ki}$ pa še zdaleč ni osamljen primer. Skladatelji v 16. stoletju so za osnovo parodičnih maš čestokrat posegali po posvetnih modelih, tudi takih s precej drzno vsebino. To problematično prakso so skušali prepovedati na zasedanju tridentinskega koncila, torej v času, ko je po virih sodeč nastala Lassova maša ${ }^{26}$ Lassov izbor predloge $s$ tako posvetno vsebino bi lahko razumeli kot zavestno odločitev, ki kaže skladateljev pogled na uporabo posvetnih modelov: poglavitni dejavnik pri izboru so glasbene kvalitete predloge. Temu v prid gotovo govori Sermisyjeva prefinjena glasba nasproti uglasbljenemu trivialnemu besedilu. ${ }^{27}$ Dodali bi lahko še povezovanje parodične tehnike komponiranja s konceptom imitatio, ki je bil poznan in prevzet iz antične retorike. ${ }^{28}$ Pri tem gre za zavestno uporabo glasbenega gradiva določene že obstoječe skladbe, ki služi za osnovo pri komponiranju novega dela, namen pa je izkazati spoštovanje skladatelju modela (navadno uveljavljenemu in cenjenemu, kar je Sermisy gotovo bil) ali pa prekašati model sam. ${ }^{29}$

Pri izboru predloge za mašo bi lahko pomembno vlogo odigrala tudi vzpostavitev neke vrste vsebinske povezave med predlogo in mašo, ki po besedah Ignaca Bossuyta »tako njemu [skladatelju] samemu kot tudi poslušalcem predstavlja intelektualni izziv« $3^{30}$ Težko si je namreč predstavljati, da bi Lasso povsem obšel besedilo predloge. Tako bi besedilo šansone pod vplivom mašnih besedil lahko razumeli tudi takole: $v$ prašičevih nespodobnih opravilih, ki jih opisuje šansona, bi lahko prepoznali naše lastne, neprebavljive nečednosti, človeško grešnost, ki potrebuje odrešitev.

Domneva, da je bila Lassova izbira pariške šansone za predlogo maše povezana $\mathrm{z}$ njegovimi morebitnimi osebnimi cilji $\mathrm{v}$ tistem času - dobiti zaposlitev na francoskem dvoru, s katerim naj bi bil tedaj v stikih -, ostaja zaradi pomanjkanja dokazov odprta. ${ }^{11}$

25 Gl. npr. McKinnon idr., »Mass.«

26 Več o obravnavi glasbe na koncilu gl. Monson, „Council of Trent Revisited,« 1-37.

27 Pri tem morebiti ni zanemarljivo, da Sermisyjeva šansona Je ne menge point de porc ni bila zelo razširjena in posledično širše poznana. $V$ večini Lassove maše poslušalci tako najverjetneje niso povezovali z njeno predlogo. Drugače pa je bilo pri njenih prepisovalcih - v nekaterih rokopisih je namreč naslovljena kot Missa brevis ali Missa sine nomine.

28 Imitatio v zvezi z glasbo omenjajo nekateri glasbeni teoretiki 16. stoletja, med njimi denimo Gioseffo Zarlino in Pietro Aaron.

29 Burkholder, »Borrowing."

30 Bossuyt in Schmid, »Lassus, « 1299.

31 Gl. Leuchtmann, Orlando di Lasso, 83-86 in 92-96; Freedman, »From Munich to Paris, « 143. 
Še vedno pa se zastavlja vprašanje, ali ni Lasso s tem, ko je prevzel Sermisyjevo šansono Je ne menge point de porc, mašo - to častitljivo liturgičnoglasbeno obliko - profaniral?

Zdi se, da je skladatelju uspelo doseči nekaj drugega, nasprotnega: s tem, ko je mojstrsko uporabil kompozicijske prvine modela in glasbeno gradivo predloge tekom maše svobodno preoblikoval, je dosegel duhovno metamorfozo šansone. $V$ tem pogledu je Lassova glasba, ki ima osnovo v tako rekoč trdni prizemljenosti, usmerjena kvišku, proti nebu.

Čeprav sodobna muzikologija obravnavani Lassovi maši (prav tako kot drugim podobnim mašam iz njegovega zgodnjega obdobja) ni posvetila velike pozornosti in ji je $\mathrm{v}$ preteklosti pogosto pripisovala obroben pomen, pa o njeni priljubljenosti med drugim pričajo številni prepisi iz druge polovice 16. in prve polovice 17., na katere naletimo širom Evrope. Mednje sodita tudi rokopisa iz Narodne in univerzitetne knjižnice.

Lassovo mašo lahko pravilno ocenimo, če prevzamemo tedanji pogled na polifono mašo 15 . in 16. stoletja: vrednost le-te je $\mathrm{v}$ njeni socialno-religiozni vlogi, s kompozicijskega stališča pa nudi skladatelju možnost izkazovanja spretnosti v kompozicijski razgibanosti, ki lahko preseže enoličnost ponavljajoče se uporabe istega glasbenega materiala. Kot poudarja Allan W. Atlas, polifone maše - in to velja tudi za obravnavano - tako ni odlikovala zgolj oblikovna zaokroženost vseh stavkov maše v zaključeno celoto, temveč aristotelski koncept raznolikosti znotraj enovitosti. ${ }^{32}$

Lassova maša je $\mathrm{v}$ svojem okolju gotovo izpolnjevala natančno določeno funkcijo. Zaradi jedrnatosti predstavlja liturgičnoglasbeno delo, primerno za mašno bogoslužje, ki nima prazničnega značaja. ${ }^{33}$ Tako si jo je mogoče predstavljati kot del jutranjega neprazničnega bogoslužja, osredinjenega na mašno daritev - jutranja obredja so bila namreč na münchenskem dvoru, kjer je skladatelj deloval, del vsakdana, pri čemer je bil mašni ordinarij vedno pet večglasno. ${ }^{34}$ Sermisyjeva šansona je spričo tega, da ni obsežna, obenem pa je razgibana, gotovo služila kot prikladno glasbeno izhodišče za snovanje maše, primerne za krajše bogoslužje. Lasso se ob tem izkaže kot vešč, razgledan skladatelj, ki je znal skrbno izbrati predlogo s točno določenimi glasbenimi značilnostmi in jo popolnoma prikrojiti lastnim potrebam, tako kot to znajo le veliki mojstri.

32 Atlas, "Music for the Mass, « 101-102.

33 Roche, Lassus, 20.

34 Perkins, Music in the Age of the Renaissance, 949. Da je bila maša del repertoarja münchenske kapele, priča denimo njena prisotnost v korni knjigi (D-Mbs, Mus Ms 2746), ki je bila namenjena pevcem kapele. 


\section{BIBLIOGRAFIJA}

\section{Glasbeni rokopisi}

Ljubljana, Narodna in univerzitetna knjižnica, Rokopisna zbirka (SI-Lnr), Ms 232. Ljubljana, Narodna in univerzitetna knjižnica, Rokopisna zbirka (SI-Lnr), Ms 285. München, Bayerische Staatsbibliothek, Musikabteilung (D-Mbs), Mus Ms 2746.

\section{Glasbeni tiski}

Quart livre contenant xxvii chansons nouvelles a quatre parties. Pariz: Attaingnant in Jullet, 1538.

Lasso, Orlando di. Messen 1-9: Messen der Drucke Venedig 1570 und München 1574. Orlando di Lasso, Sämtliche Werke, Neue Reihe 3. Kassel: Bärenreiter, 1962. . Missa quatuor vocum ad imitationem moduli. Pariz: Ballard, 1687.

- Quinque missae. Benetke: Correggiato, 1570.

Paix, Jacob. Missa: Parodia mottetae Domine da nobis auxilium Th. Crequilonis. Lauingen: Reinmichaelius, 1587.

Sermisy, Claudin de. Opera omnia. Zv. 3, Chansons. Uredila Gaston Allaire in Isabelle Cazeaux. Corpus mensurabilis musicae 52. S. 1.: American institute of Musicology, 1974 .

Druga literatura

Ambros, August Wilhelm. Geschichte der Musik. Breslau: Leuckart, 1876.

Atlas, Allan W. "Music for the Mass." V: James Haar, ur., European Music, 1520-1640, Studies in Medieval and Renaissance Music 5, 101-29. Woodbridge: Boydell Press, 2006.

Bossuyt, Ignace, in Bernhold Schmid. »Lassus«. V: Ludwig Finscher, ur., Die Musik in Geschichte und Gegenwart, Personenteil, 10: 1244-1306. Kassel: Bärenreiter; Stuttgart: Metzler, 1998.

Brinzig, Armin, Georg von Dadelsen, Hartmut Schick in Reinhard Schulz. »Parodie und Kontrafaktur«. V: Ludwig Finscher, ur., Die Musik in Geschichte und Gegenwart, 2. izd., Sachteil, 7:1394-1416. Kassel: Bärenreiter; Stuttgart: Metzler, 1997.

Brown, Howard M., in Louise K. Stein. Music in the Renaissance. 2. izd. Upper Saddle River, New Jersey: Prentice Hall, 1999.

Burkholder, J. Peter. »Borrowing.» V: Grove Music Online. Http://www.oxfordmusiconline.com.nukweb.nuk.uni-lj.si/subscriber/article/grove/music/52918pg5 (obiskano 2. oktobra 2012).

Cazeaux, Isabelle. Uvod v: Gaston Allaire in Isabelle Cazeaux, ur., Claudin de Sermisy, Opera omnia, zv. 3, Chansons, Corpus mensurabilis musicae 52, xi-xii. S. 1.: American institute of Musicology, 1974.

Cerone, Pietro. El melopeo y maestro: tractado de música theorica y pratica. Neapelj: Gargano in Nucci, 1613. Faksimilirana izdaja, ur. Antonio Ezquerro Esteban. Monumentos de la música española 74. 2 zv. Barcelona: Consejo Superior de Investigaciones Cientificas, 2007.

Freedman, Richard. »From Munich to Paris: Orlando di Lasso, Adrian Le Roy, and Listeners at the Royal Court of France.« V: Theodor Göllner in Bernhold Schmid, ur., 
Die Münchner Hofkapelle des 16. Jahrhunderts im europäischen Kontext: Bericht über das internationale Symposion der Musikhistorischen Kommission der Bayerischen Akademie der Wissenschaften in Verbindung mit der Gesellschaft für Bayerische Musikgeschichte München, 2.-4. August 2004, 143-59. München: Verlag der Bayerischen Akademie der Wissenschaften, 2006.

Kokole, Metoda. "The Musical Repertoire Cultivated on the Territory of Modern Slovenia (1567-c. 1620) and Its Possible Connections with the Court Chapel in $\mathrm{Mu}-$ nich«. V: Theodor Göllner in Bernhold Schmid, ur., Die Münchner Hofkapelle des 16. Jahrhunderts im europäischen Kontext: Bericht über das internationale Symposion der Musikhistorischen Kommission der Bayerischen Akademie der Wissenschaften in Verbindung mit der Gesellschaft für Bayerische Musikgeschichte München, 2.-4. August 2004, 171-90. München: Verlag der Bayerischen Akademie der Wissenschaften, 2006.

Leuchtmann, Horst. Orlando di Lasso. Zv. 1: Sein Leben: Versuch einer Bestandsaufnahme der biographischen Einzelheiten. Wiesbaden: Breitkopf \& Härtel, 1976.

Leuchtmann, Horst, in Bernhold Schmid. Seine Werke in zeitgenössischen Drucken, 15551687. Orlando di Lasso: Sämtliche Werke, Supplement. 2 zv. Kassel: Bärenreiter, 2001.

Lockwood, Lewis. "On 'Parody' as Term and Concept in Sixteenth-Century Music." V: Jan La Rue, ur., Aspects of Medieval and Renaissance Music: A Birthday Offering to Gustave Reese, 560-75. New York: Norton, 1966.

McKinnon, James W., idr. »Mass.« V: Grove Music Online. Http://www.oxfordmusiconline.com.nukweb.nuk.uni-lj.si/subscriber/article/grove/music/45872 (obiskano 2. oktobra 2012).

Monson, Craig A. Monson. »The Council of Trent Revisited." Journal of the American Musicological Society 55, št. 1 (2002): 1-37.

Orlich, Rufina. Die Parodiemessen von Orlando di Lasso. Studien zur Musik 4. München: Wilhelm Fink Verlag, 1985.

Perkins, Leeman L. Music in the Age of the Renaissance. New York: Norton, 1999.

Pontio, Pietro. Ragionamento di musica. Parma: Viotto, 1588. Faksimilirana izdaja, ur. Suzanne Clercx. Documenta musicologica 16. Kassel: Bärenreiter, 1959.

Roche, Jerome. Lassus. Oxford Studies of Composers 19. London: Oxford University Press, 1982.

Schalz, Nicolas. Studien zur Komposition des Gloria: musikal. Formgestaltung von d. Gregorianik bis zu Monteverdi. Frankfurter Beiträge zur Musikwissenschaft 3. Tutzing: Schneider, 1980.

Wagner, Peter. Geschichte der Messe. Leipzig: Breitkopf \& Härtel, 1913. 


\section{JE NE MENGE POINCT DE PORCQ: ORLANDO DI LASSO'S EARLY PARODY MASS}

\section{Summary}

One of the most remarkable $16^{\text {th }}$-century composers was Orlando di Lasso (1530/1532-1594), perhaps the most prominent musician of his time. In the second half of the $16^{\text {th }}$ and the early $17^{\text {th }}$ centuries, his works were widespread across Europe, especially in its central and western part. Some of the surviving contemporary sources of Lasso's music - both printed and manuscript - are preserved in Slovenian libraries and archives. Among them are two incompletely preserved manuscripts, dating from ca. 1600, today kept at the National and University Library in Ljubljana (Ms 232 and Ms 285). They both contain Lasso's Missa super Je ne menge poinct de porcq, first published in Lasso's second book of Masses, Quinque missae, by Claudio Merulo in 1570. Interestingly, this early Munich-period Mass is based on a Parisian chanson by Claudin de Sermisy (ca. 1490-1562), whose content is unequivocally scatological.

It was quite common for $16^{\text {th }}$-century composers to base their settings of the Mass Ordinary on pre-existent polyphonic compositions, whether sacred or secular. One of the rare descriptions of this technique - widely known as parody technique - is given in Pietro Cerone's El melopeo y maestro (1613). It can serve as the basis for an elementary analysis of how Lasso employed Sermisy's chanson Je ne menge point de porc. The analysis shows that Lasso, for various reasons, does not always follow the established practices as they can be observed from Cerone's treatise. Nevertheless he demonstrates significant skill in utilising borrowed material to compose his parody Mass. Lasso's Missa super Je ne menge poinct de porcq is particularly intriguing due to its use of Sermisy's chanson; what could be the reason for Lasso's decision to use Sermisy's profoundly secular chanson in order to compose a Mass setting? Although the answer can be multifaceted (such as an intention to establish a special textual relation between the Mass and the model), the principal reason seems to be the musical qualities of the chanson, which proved to be a very convenient and worthy source for composing a short Mass. 